\title{
Pengaruh jumlah sekat vertikal dan debit aliran terhadap viskositas oli pada separator air oli
}

\author{
I. Qiram* \\ Teknik Mesin, Fakultas Teknik, Universitas PGRI Banyuwangi, Jl. Ikan Tongkol 22 Banyuwangi \\ Jawa Timur 68416, Indonesia, Telp. (0333) 421593, 423639 \\ *Email: ikhwanulqiram@gmail.com
}

\section{ARTICLE INFO}

Article History:

Received 17 December 2016

Accepted 2 February 2017

Available online 30 Juni 2017

\author{
Keywords: \\ Separator \\ Vertical divider \\ Oil \\ Viscocity
}

\begin{abstract}
Water pollution is a major environment problem. Oil water separator can be used to solve this problem. This research is aimed to get the effect of vertical divider number and fluid flow rate due to oil viscosity. The research is done by experiment using gravity separator. Vertical dividers are varied as 5 and 7 . Fluid flow rate is vary as 176,5; 106,6; 53,7 and 33,7 ml/s. Oil 0,5 litre is mixture with 10 litres of water. Oil viscosity is measured with simple flow gravity method. The data is analized statistically using SPSS 17.0. The result shows that vertical divider number and fluid flow rate have effect on oil viscosity.
\end{abstract}

\section{PENDAHULUAN}

Salah satu dampak perkembangan jaman adalah masalah pencemaran lingkungan, salah satunya adalah pencemaran air. Masalah pencemaran air merupakan suatu permasalahan yang serius, mengingat populasi manusia dan kebutuhan akan air yang semakin meningkat. Salah satu penyebab pencemaran air adalah pencemaran oli oleh bengkel-bengkel otomotif, baik bengkel servis, ganti oli maupun bengkel cuci. Pencemaran ini lebih banyak disebabkan karena adanya tumpahan oli yang langsung terbawa air ke saluran umum dan selanjutnya mencemari seluruh daerah aliran air tersebut.

Oli bekas adalah limbah yang mengandung logam berat dari bensin atau mesin bermotor. Apabila logam berat tersebut masuk ke dalam tubuh kita dan terakumulasi, maka akan mengakibatkan kerusakan ginjal, syaraf, dan penyakit kanker. Berdasarkan kriteria, oli bekas termasuk kategori limbah B3 (Bahan Berbahaya dan Beracun). Limbah B3 adalah limbah yang sangat berbahaya, karena bersifat korosif, mudah terbakar, mudah meledak, reaktif, beracun, menyebabkan infeksi, iritan, mutagenik, dan radioaktif (Rachman, 2013).

Bengkel-bengkel otomotif (mobil dan sepeda motor) memiliki beberapa potensi limbah Bahan Berbahaya dan Beracun (B3). Limbah B3 adalah limbah yang sangat berbahaya, karena bersifat korosif, mudah terbakar, mudah meledak, reaktif, beracun, menyebabkan infeksi dan bersifat iritan (Anonimous, 2013). Aktivitas kerja di bengkel otomotif melibatkan banyak bahan yang mengandung potensi ini. Salah satu bahan yang termasuk kategori ini adalah oli. Oli yang digunakan dalam pengoperasian kendaraan, perawatan dan dalam bentuk proses perbaikan akan menghasilkan limbah oli bekas.

Aktivitas-aktivitas bengkel otomotif terkait dengan fluida oli, minyak dan air. Aktivitas ini antara lain proses pencucian komponen mesin dan kendaraan. Oli yang tercampur dalam air akan terbuang ke saluran umum atau sungai dan mengalir ke laut. Aktivitas lainnya adalah proses penggantian oli, penanganan perlengkapan ganti oli, limbah kaleng bekas oli dan lain-lain. 
Tumpahan oli dapat meresap ke tanah atau terbawa oleh air hujan.

Salah satu aplikasi yang dapat diterapkan adalah separator air-oli. Separator air yang bercampur oli adalah sistem yang mengolah air buangan yang bercampur oli untuk menghasilkan derajat kontaminasi yang aman sebelum air dibuang ke saluran umum. Separator digunakan untuk memisahkan air dari oli atau minyak sebelum dibuang dari lambung kapal (Desmukh dkk, 2013). Separator menggunakan komponen pemisah mekanis berupa membran yang digunakan pada pengolahan limbah emulsi minyaair sintetis (Aryanti dkk, 2013).

Penelitian tentang unjuk kerja separator serupa telah banyak dilakukan, seperti halnya unjuk kerja separator pada kapal perikanan skala laboratorium (Wibowo dkk, 2014), dan studi kasus efisiensi penggunaan oil water separator pada kapal penangkap ikan untuk pencegahan pencemaran minyak di laut yang dilakukan oleh (Setiawan dkk, 2014). Unjuk kerja separator pada pengolahan limbah di Industri makanan yang dikerjakan oleh (Ankyu dan Noguchi, 2014), Efisiensi pengolahan limbah cair mengandung minyak pelumas pada oil separator dengan menggunakan plate settler yang dikerjakan oleh (Pratiwi dan Hermana, 2014).

Penelitian sejenis yang dilakukan dengan simulasi pernah dilakukan yaitu untuk aliran multiphase separator air-minyak pada proses penyulingan oleh (Zhang dkk, 2013), separator 3 fase pada industri minyak oleh (Jahangiri dan Nouri, 2014). separator tabung inklanasi oleh (Chen dkk, 2015). Penelitian yang mirip dengan penelitian yang sedang dilakukan ini adalah penelitian untuk mendapatkan pengaruh kecepatan campuran (mixture velocity) dan diameter droplet pada separator oli dengan model simulasi oleh (Abdulkadir dan Hernandez-Perez, 2010), penelitian pengaruh jumlah sudu penghalang (buffle) yang dilakukan oleh (Agunwamba dkk, 2013), studi pengaruh aspek rasio air-oli terhadap efisiensi separator konvensional oleh (Odiete dan Agunwamba, 2016).

Semua penelitian tersebut di atas menunjukkan bahwa terdapat pengaruh kecepatan campuran dan diameter droplet terhadap kinerja separator. Semakin besar kecepatan campuran memperlambat fase separasi dan semakin besar diameter droplet akan menghasilkan fase separasi yang lebih baik (Abdulkadir dan Hernandez-Perez, 2010). Sudut kemiringan pelat separator $60^{\circ}$ dan konsentrasi minyak pelumas dalam influent 150 $\mathrm{mg} / \mathrm{L}$ memberikan efisiensi tertinggi, yakni $84,93 \%$. Sudut $60^{\circ}$ berdasarkan hasil penelitian diketahui pula merupakan sudut yang paling optimum untuk proses pemisahan minyak pelumas dengan air
(Pratiwi dan Hermana, 2014). Jumlah sudu penghalang berpengaruh terhadap efisiensi separator. Efisiensi semakin besar jika jumlah sudu bertambah. Efisiensi pemisahan oli meningkat dengan semakin besarnya aspek rasio air/oli (Odiete dan Agunwamba, 2016).

Penelitian ini bertujuan untuk mendapatkan pengaruh jumlah sekat vertikal dan debit aliran terhadap viskositas oli pada separator air oli. Sekat vertikal dalam hal ini adalah sekat pembatas separator tipe gravitasi.

\section{Pencemaran air oleh oli}

Penanganan oli bekas sebagai limbah sangat dianjurkan karena masalah dampak lingkungan. Satu pint (setara 0,586 liter) dapat mengakibatkan lapisan tipis sebesar 35 parts per million pada permukaan air seluas satu acre (setara 0,4646 ha). Ketika oli dibuang ke air, oli bekas meningkatkan kebutuhan oksigen makhluk hidup karena terjadi proses dekomposisi hidrokarbon. Proses ini melepaskan kandungan oksigen yang dibutuhkan makhluk hidup.

Akibat pencemaran minyak bumi di laut adalah (Anshari, 2013):

1. Rusaknya estetika pantai akibat bau dari material minyak.

2. Kerusakan biologis, bisa merupakan efek letal dan subletal.

3. Pertumbuhan fitoplankton laut akan terhambat akibat keberadaan senyawa beracun dalam komponen minyak bumi, juga senyawa beracun yang terbentuk dari proses biodegradasi.

4. Penurunan populasi alga dan protozoa akibat kontak dengan racun slick (lapisan minyak di permukaan air

\section{Prinsip kerja separator}

Teori pemisahan minyak dari air buangan didasarkan pada tingkat naiknya (rise rate) partikel minyak ke permukaan dan hubungannya terhadap tingkat pembebanan permukaan (surface-loading rate) separator. Tingkat kecepatan vertikal dimana partikel minyak bergerak menuju permukaan separator adalah akibat dari perbedaan kerapatan minyak dan fase air pada air buangan. Kecepatan vertikal butiran minyak dihitung dengan persamaan Stokes (Hukum Stokes) yaitu (Sutikno, 2005):

$$
\begin{aligned}
& v_{r}=\frac{g}{18 \mu}\left(\rho_{w}-\rho_{o}\right) d^{2} \\
& v_{r}=0,0123\left(\frac{S_{w}-S_{o}}{\mu}\right)
\end{aligned}
$$

\section{Dengan:}

$v_{r}=$ kecepatan vertikal butiran $(\mathrm{m} / \mathrm{s})$

$g=$ percepatan gravitasi bumi $\left(9.81 \mathrm{~m} / \mathrm{s}^{2}\right)$

$\mu=$ viskositas 
$\rho_{w}=$ kerapatan air $\left(\mathrm{kg} / \mathrm{m}^{3}\right)$

$\rho_{o}=$ kerapatan minyak $\left(\mathrm{kg} / \mathrm{m}^{3}\right)$

$d=$ diameter butiran minyak $(\mathrm{mm})$

$S_{w}=$ Saturasi air

$S_{0}=$ Saturasi minyak

Tetapi hukum Stokes hanya berlaku pada fluida diam (tidak mengalir). Menurut hukum ini, droplet oli berdiameter 100 micron akan naik 15 $\mathrm{cm}$ dalam air setiap 10 menit. Droplet berdiameter 20 micron memerlukan waktu 2 jam untuk jarak yang sama. Karena droplet oli harus naik $120 \mathrm{~cm}$ pada separator gravitasi yang umum digunakan maka droplet berukuran kecil umumnya tidak dapat dikumpulkan.

\section{Jenis Separator}

1. Separator Gravitasi (Gravity Separator). Separator ini menggunakan prinsip pemisahan yang memanfaatkan beda berat jenis minyak dan air. Minyak yang memiliki densitas lebih rendah akan mengambang dan membentuk lapisan tipis di atas permukaan air.

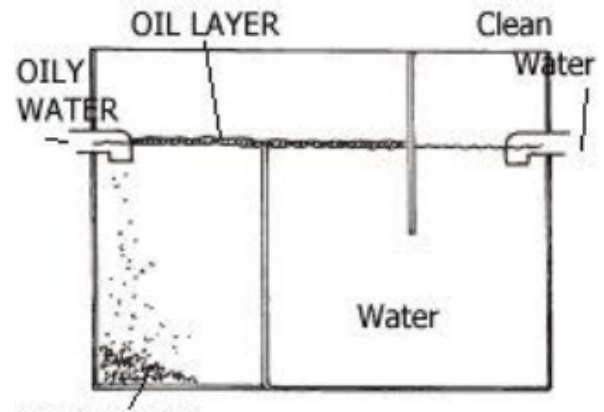

Settled Solids

Gambar 1. Separator gravitasi, Deshmukh dkk., 2013

2. API Separator.

API separator didesain oleh American Petroleum Institute yang menggunakan hukum Stokes untuk mendapatkan kecepatan naik droplet minyak berdasarkan densitas dan ukuran.

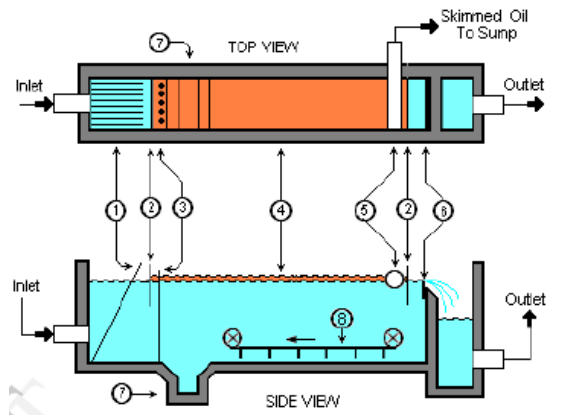

Gambar 2. API separator, Deshmukh dkk., 2013

3. Separator Pelat Parallel (Parallel Plate Separator).
Separator ini hampir sama dengan $A P I$ separator tetapi dilengkapi dengan pelat-pelat parallel. Pelat-pelat ini berfungsi sebagai permukaan bagi droplet oli untuk berkumpul dan memberikan alur bagi sedimen untuk mengendap.

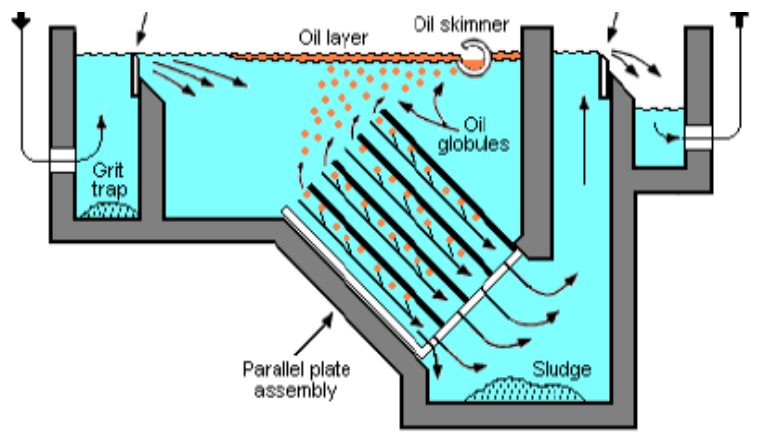

Gambar 3. Separator pelat parallel, Deshmukh dkk., 2013

4. Separator Sentrifugal (Centrifugal Separator). Separator ini memisahkan air dan oli dengan prinsip sentrifugal. Sistem ini umumnya terdiri dari tabung yang berputar di dalam wadah yang diam. Fluida yang memiliki densitas lebih besar yaitu air akan terkumpul di sekeliling wadah dan diambil dari dinding wadah sedangkan oli terakumulasi di sumbu putaran dan diambil dari pusat sumbu tersebut.

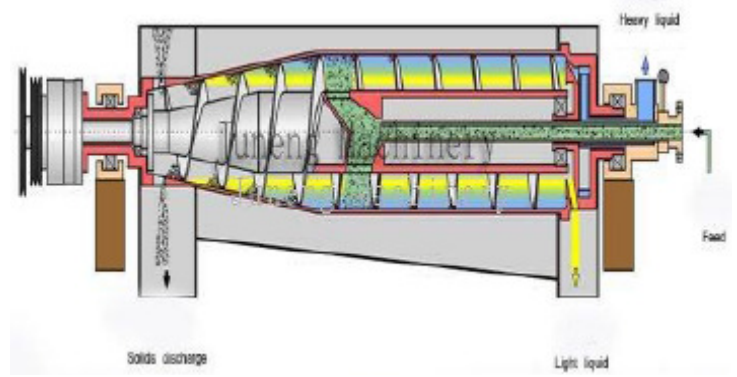

Gambar 4. Separator sentrifugal, Deshmukh dkk., 2013

\section{METODE PENELITIAN}

Variabel penelitian

1. Variabel bebas jumlah sekat vertikal 3,5 dan 7 , debit aliran 176,$5 ; 106,6 ; 53,7$ dan $33,7 \mathrm{ml} / \mathrm{dt}$ (liter/detik).

2. Variabel terikat meliputi perbandingan viskositas oli sebelum dan sesudah proses separasi.

\section{Rancangan percobaan}

Peralatan penelitian didesain dengan pertimbangan metode gravitasi dan metode hydrocyclone yang dimodifikasi menjadi aliran zigzag, jumlah tahapan pemisahan dan laju aliran yang relatif kecil. Model-model separator yang diuji adalah :

a. Model separator 3 sekat vertikal (3SV). 
b. Model separator 5 sekat vertikal (5SV).

c. Model separator 7 sekat vertikal (7SV).

Jumlah sekat yang ganjil dimaksudkan agar saluran masuk dan saluran keluar berada pada posisi garis sumbu yang sama. Pada desain ini diharapkan oli akan mengapung ke atas pada area antara sekat 1 dan 2 serta area antara sekat 2 dan sekat 3. Lubang sekat yang dibuat selang-seling dimaksudkan agar fluida menempuh jarak yang lebih besar sehingga waktu yang tersedia bagi oli untuk mengapung lebih lama.

Cara kerja peralatan penelitian:

1. Tangki atas diisi dengan 0,5 liter oli dan kemudian ditambahkan 10 liter air. Oli yang dipakai adalah oli bekas yang dibeli dari bengkel ganti oli (oli bekas oli mesin). Oli ini diukur viskositasnya terlebih dulu.

2. Campuran air dan oli diaduk selama 2 menit untuk pencampurannya.

3. Katup dibuka sesuai dengan penandaan besaran debit. Campuran air oli dibiarkan mengalir sampai habis.

\section{HASIL DAN PEMBAHASAN}

Tabel 1. Data viskositas oli sebelum separasi

\begin{tabular}{|c|c|c|c|}
\hline $\begin{array}{l}\text { Berat } \\
\text { oli (kg) }\end{array}$ & $\begin{array}{l}\text { Waktu } \\
\text { (detik) }\end{array}$ & $\begin{array}{l}\text { Panjang } \\
\text { pipa (m) }\end{array}$ & $\begin{array}{c}\text { Viskositas } \\
\text { (kg/m dt) }\end{array}$ \\
\hline 0.0436 & 1.5500 & 0.1000 & 0.2813 \\
\hline 0.0494 & 1.5800 & 0.1000 & 0.3127 \\
\hline 0.0529 & 1.6000 & 0.1000 & 0.3306 \\
\hline 0.0631 & 2.1000 & 0.1000 & 0.3005 \\
\hline 0.0530 & 20000 & 0.1000 & 0.2650 \\
\hline \multicolumn{3}{|c|}{ Rata-rata } & 0.2980 \\
\hline
\end{tabular}

Dari tabel 1, perhitungan Anova terlihat bahwa $\mathrm{F}$ ratio $>\mathrm{F}$ tabel dengan tingkat kesalahan $5 \%$ maka :

1. Jumlah sekat vertikal berpengaruh terhadap viskositas oli hasil separasi.

2. Debit berpengaruh terhadap viskositas oli hasil separasi.

3. Kombinasi jumlah sekat dan debit juga

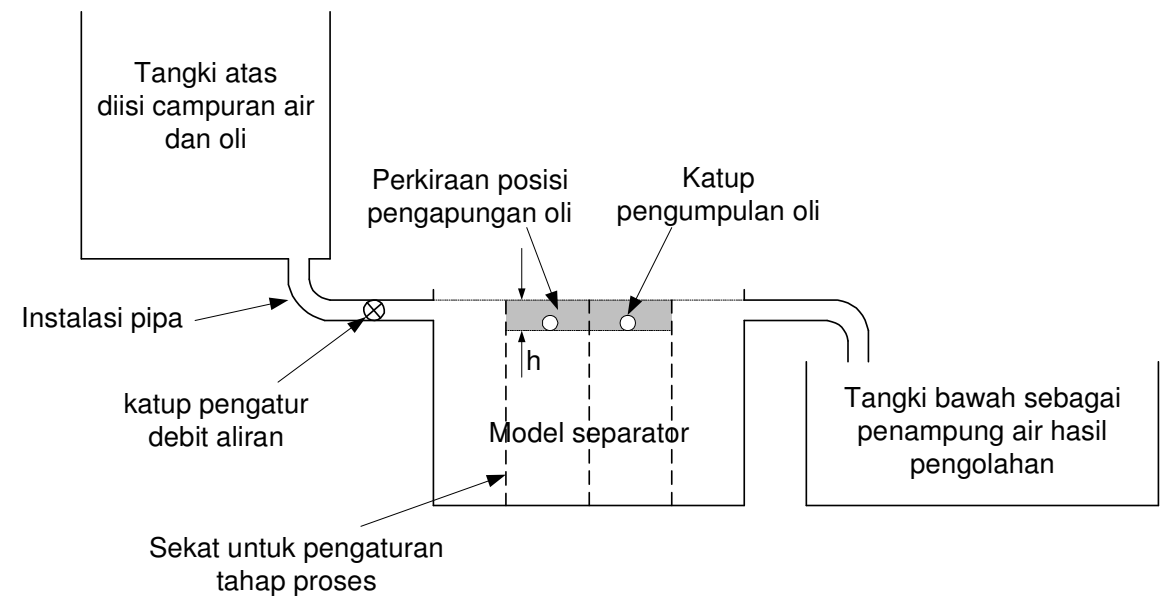

Gambar 5. Rancangan alat penelitian

4. Oli ini diambil sampelnya dan diukur viskositasnya.

5. Pengambilan data dilakukan untuk 4 variasi debit aliran.

6. Proses dilakukan dengan 5 kali pengulangan. Pengukuran viskositas:

1. Oli sampel ditimbang beratnya pada sebuah timbangan Centogram

2. Oli yang sudah ditimbang dimasukkan ke dalam tabung oli.

3. Di saat sumbat dibuka bersamaan dengan itu stopwatch dihidupkan untuk mengetahui berapa lama oli yang habis keluar dari dalam tabung. berpengaruh terhadap viskositas oli hasil separasi.

Dari gambar pada gambar 8 terlihat bahwa gambar regresi yang dihasilkan adalah bentuk persamaan umum pangkat tiga. Garis regresi yang paling mendekati kondisi sesungguhnya terjadi pada jumlah sekat tiga buah.

Dengan melihat adanya fenomena yang terjadi pada pola gambar perbandingan viskositas dan debit aliran di atas, kita dapat melihat manakah variasi jumlah sekat vertikal yang dapat meminimalisir tercampurnya oli dengan air (viskositasnya hampir sama dengan sebelum proses separasi). Pada variasi model sekat tiga 
menunjukkan oli lebih banyak mengendap pada ruang sekat pertama ini dikarenakan luasan ruang yang lebih leluasa sehingga oli tidak ikut mengalir bersama air.

Fenomena ini berbeda dengan apa yang terjadi pada variasi model sekat lima dan sekat tujuh yang menunjukkan terjadinya peningkatan seperti yang ditunjukkan pada gambar 8 . Kondisi ini dikarenakan luasan pada ruang-ruang sekatnya terlalu sempit sehingga kemungkinan oli tercampur dengan air sangat besar oleh karena itu oli tidak hanya dapat mengapung pada sekat pertama saja melainkan juga pada ruang sekat kedua dan ketiga.

\section{a. Tampak depan}

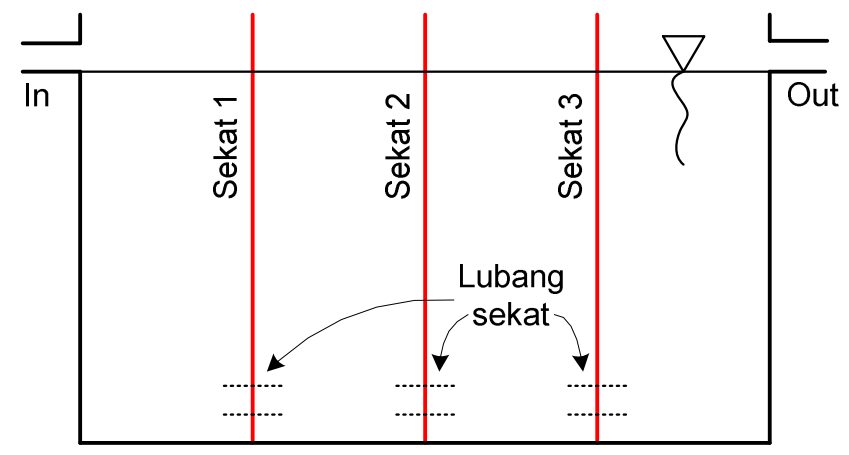

b. Tampak atas

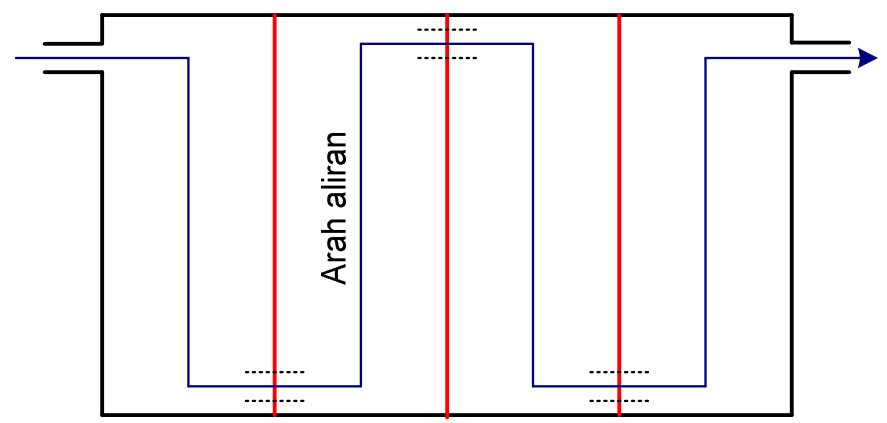

Gambar 6. Model separator 3 sekat vertikal (3SV)

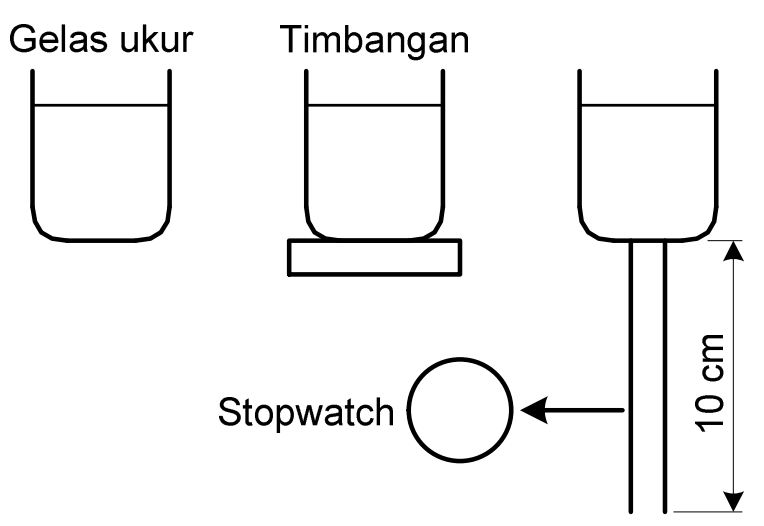

Gambar 7. Skema pengukuran viskositas 
.Tabel 2.Data viskositas oli sesudah separasi

\begin{tabular}{|c|c|c|c|c|c|c|}
\hline \multirow{2}{*}{$\begin{array}{c}\text { Jumlah } \\
\text { Sekat }\end{array}$} & \multicolumn{5}{|c|}{ Debit $176,5 \mathrm{ml} / \mathrm{s}$} & \multirow{2}{*}{$\begin{array}{l}\text { Rata } \\
\text { rata }\end{array}$} \\
\hline & 1 & 2 & 3 & 4 & 5 & \\
\hline 3 & 0.33 & 0.33 & 0.35 & 0.28 & 0.31 & 0.32 \\
\hline 5 & 0.32 & 0.31 & 0.30 & 0.32 & 0.31 & 0.31 \\
\hline 7 & 0.33 & 0.32 & 0.32 & 0.31 & 0.33 & 0.32 \\
\hline $\begin{array}{l}\text { Rata2 } \\
\text { kolom }\end{array}$ & \multicolumn{6}{|c|}{0.32} \\
\hline Jumlah & \multicolumn{5}{|c|}{ Debit 106,6 ml/s } & \multirow{2}{*}{$\begin{array}{l}\text { Rata } \\
\text { rata }\end{array}$} \\
\hline Sekat & 1 & 2 & 3 & 4 & 5 & \\
\hline 3 & 0.33 & 0.32 & 0.24 & 0.31 & 0.24 & 0.29 \\
\hline 5 & 0.22 & 0.28 & 0.29 & 0.26 & 0.22 & 0.25 \\
\hline 7 & 0.31 & 0.31 & 0.30 & 0.31 & 0.30 & 0.31 \\
\hline $\begin{array}{l}\text { Rata2 } \\
\text { kolom }\end{array}$ & \multicolumn{6}{|c|}{0.28} \\
\hline Jumlah & \multicolumn{5}{|c|}{ Debit $53,7 \mathrm{ml} / \mathrm{s}$} & \multirow{2}{*}{$\begin{array}{l}\text { Rata } \\
\text { rata }\end{array}$} \\
\hline Sekat & 1 & 2 & 3 & 4 & 5 & \\
\hline 3 & 0.31 & 0.23 & 0.31 & 0.33 & 0.31 & 0.30 \\
\hline 5 & 0.23 & 0.33 & 0.31 & 0.23 & 0.24 & 0.27 \\
\hline & 0.32 & 0.32 & 0.32 & 0.33 & 0.30 & 0.32 \\
\hline $\begin{array}{l}\text { Rata2 } \\
\text { kolom }\end{array}$ & \multicolumn{6}{|c|}{0.29} \\
\hline Jumlah & \multicolumn{5}{|c|}{ Debit $33,7 \mathrm{ml} / \mathrm{s}$} & \multirow{2}{*}{$\begin{array}{c}\text { Rata } \\
\text { rata }\end{array}$} \\
\hline Sekat & 1 & 2 & 3 & 4 & 5 & \\
\hline 3 & 0.30 & 0.34 & 0.34 & 0.34 & 0.28 & 0.32 \\
\hline 5 & 0.21 & 0.22 & 0.22 & 0.22 & 0.22 & 0.22 \\
\hline 7 & 0.19 & 0.28 & 0.19 & 0.21 & 0.20 & 0.21 \\
\hline $\begin{array}{l}\text { Rata2 } \\
\text { kolom }\end{array}$ & \multicolumn{6}{|c|}{0.25} \\
\hline
\end{tabular}

Tabel 3. Statistik Anova

\begin{tabular}{cccccc}
\hline & Sum of & \multicolumn{1}{c}{ Mean } & & \\
\hline Sumber & Square & df & Square & F Ratio & F Tabel \\
Sekat & 0.1522 & 2 & 0.076 & 60.10 & 3.29 \\
Debit & 1.9080 & 3 & 0.636 & 502.3 & 2.90 \\
Interaksi & 0.3231 & 6 & 0.054 & 42.5 & 2.40 \\
Residual & 0.0405 & 32 & 0.0013 & & \\
Total & 2.4238 & 43 & & & \\
\hline
\end{tabular}




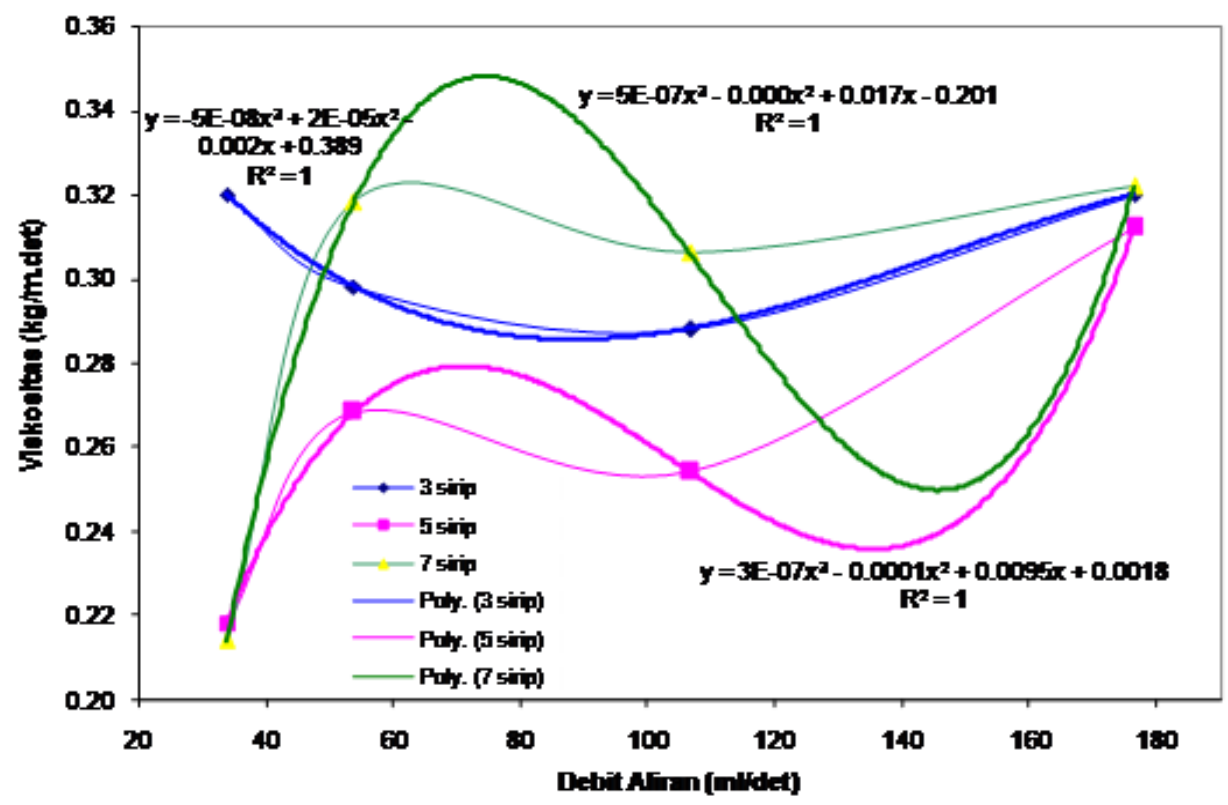

Gambar 8. Perbandingan viskositas dan debit aliran

Tabel 3. Regresi

\begin{tabular}{ccccc}
\hline Jumlah & \multicolumn{4}{c}{ Debit $(\mathrm{ml} / \mathrm{s})$} \\
sekat & 176.5 & 106.6 & 53.7 & 33.7 \\
\hline 3 & 0.32 & 0.29 & 0.30 & 0.32 \\
5 & 0.31 & 0.25 & 0.27 & 0.22 \\
7 & 0.32 & 0.31 & 0.32 & 0.21 \\
\hline
\end{tabular}

Perbedaan viskositas yang terjadi pada beberapa variasi model sekat vertikal ini juga sangat dipengaruhi dengan adanya variasi debit aliran. Aliran yang terjadi pada air akan menyebabkan oli pecah menjadi butiran-butiran kecil (droplet) dalam berbagai ukuran. Proses ini menyebabkan butiran-butiran ini bercampur dengan air. Proses terjadinya butiran ini semakin cepat terjadi jika kondisi aliran kecepatan tinggi atau turbulen. Tercampurnya butiran-butiran oli ini dinamakan dengan dispersi (dispersion). Dalam aplikasinya, separator menggunakan hukum Stokes yang berkaitan dengan laju pengendapan (settling velocity) yaitu laju partikel padat atau cair pada media fluida air atau udara. Aplikasi praktisnya menyangkut bidang penentuan viskositas, polusi air dan udara, proses fluidisasi dan jenis aliran dua fase lainnya dimana terjadi gerak relatif yang sangat kecil antara partikel dan fluidanya (Brodkey dan Hershey, 1988).

Dari foto pandangan atas terlihat bahwa pada tiga model variasi sekat vertikal terjadi pengumpulan oli di ruang pertama. Hal ini disebabkan karena debit aliran yang relatif kecil dan tinggi separator yang relatif besar sehingga oli tidak dapat mencapai dasar separator dan pindah ke ruang berikutnya.
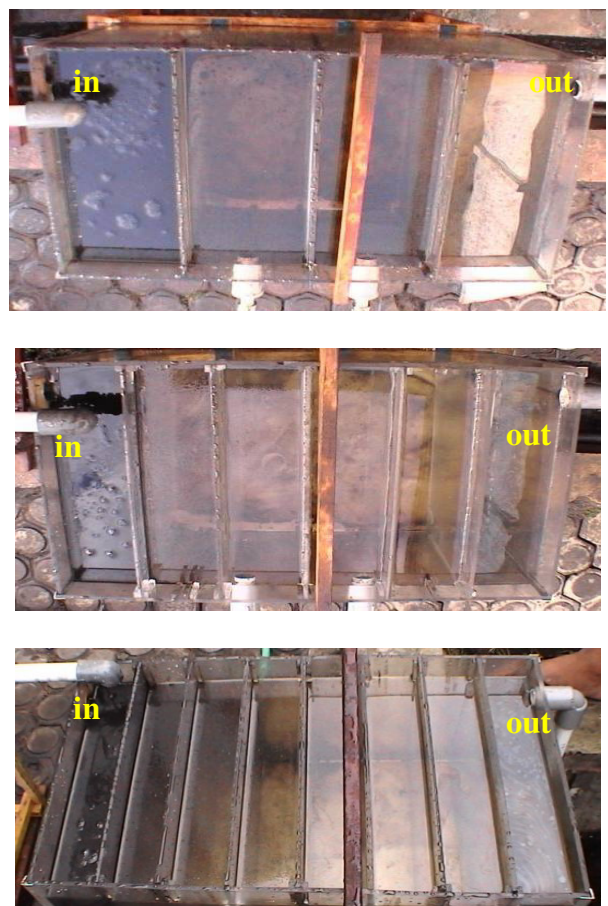

Gambar 9. Foto hasil percobaan, sisi kiri saluran masuk dan sisi kanan keluar

Pada tiga model sekat juga terlihat bahwa masih terjadi lapisan yang sangat tipis pada ruang kedua dan seterusnya sehingga air yang keluar dari proses separasi masih mengandung sedikit 
oli. Tipisnya lapisan oli ini terlalu sulit untuk diukur untuk melihat perbedaan yang terjadi.

\section{KESIMPULAN}

Berdasarkan hasil penelitian dan perhitungan maka dapat diambil kesimpulan sebagai berikut :

1. Jumlah sekat vertikal berpengaruh terhadap proses separasi (berpengaruh terhadap viskositas oli hasil separasi).

2. Debit aliran berpengaruh terhadap proses separasi (berpengaruh terhadap viskositas oli hasil separasi).

3. kombinasi jumlah dan debit aliran berpengaruh terhadap viskositas oli hasil separasi.

\section{DAFTAR PUSTAKA}

Abdulkadir M., Hernandez-Perez V., 2010, The effect of mixture velocity and droplet diameter on oil-water separator using computational fluid dynamics (CFD), World Academy of Science, Engineering and Technology, 61, 35-43.

Agunwamba J.C., Kingsley U., Chinelo O., 2013, Effect of baffles on oil water separator, INT J CURR SCl 2013, 7, 146-152.

Ankyu E., Noguchi R., 2014, Economical evaluation of introducing oil-water separation technology to wastewater treatment of food processing factory based on separation engineering, Agriculture and Agricultural Science Procedia, 2, 67-73.

Anonimous, 2013, Manajemen limbah pada bengkel, http://www.gunadarma.ac.id.

Anshari I, 2013, Limbah minyak, http://www. ansolahlimbah.blogspot.com.

Aryanti N., Prihatiningtyas I., Wardhani D.H., Ikhsan D., 2013, Kinerja membran ultrafiltrasi untuk pengolahan limbah emulsi minyak-air sintetis, Reaktor, 14(4), 277-283.

Brodkey R.S., Hershey H.C., 1988, Transport phenomena, Erlangga, Jakarta.

Chen L., Wu S., Lu H, Huang K., Zhao L., 2015 , Numerical simulation and structural optimization of the inclined oil/water separator, Plos One DOI:10.1371/ journal.pone.0124095, 1-15.

Deshmukh S.R., Jagadeesan P., Chandra A., Raut P., 2013, Bilge oil-water separator, International Journal of Engineering Research \& Technology (IJERT), 2(7), 15551561.

Jahangiri M.R., Nouri M., 2014, Simulation of three-phase separator in petroleum industry, Journal of Chemical and Pharmaceutical Research, 6(11), 923-936.

Odiete W.E., Agunwamba J.C., 2016, Effect of aspect ratio on the oil separation efficiency of conventional oil/water separators, International Journal of Scientific \& Engineering Research, 7(3), 840-846.

Pratiwi K.D.S., Hermana J., 2014, Efisiensi pengolahan limbah cair mengandung minyak pelumas pada oil separator dengan menggunakan plate settler, Jurnal Teknik Pomits, 3(1), D5-9.

Rachman A.M., 2013, Manajemen terhadap limbah bengkel, Fakultas Teknologi Industri, Jurusan Teknik Mesin, Universitas Gunadarma, Depok.

Setiawan T.E., Haeruddin, Ain C., 2014, Efisiensi penggunaan oil water separator pada kapal penangkap ikan untuk pencegahan pencemaran minyak di laut (Studi Kasus KM. Mantis) di BBPPI Semarang, Diponegoro Journal Of Maquares, 3(3), 112-120.

Sutikno S., 2005, Optimasi perancangan model hidraulika untuk memisahkan limbah minyak pada air buangan, Jurnal Sains dan Teknologi, 4(2), 53-57.

Wibowo T.W., Boesono H., Setiyanto I., 2014, Uji performansi alat pemisah limbah cair berminyak (Oily Water Separator) untuk kapal perikanan dalam skala laboratorium, Journal of Fisheries Resources Utilization Management and Technology, 3(4), 1-9.

Zhang X., Cheng Y., Nie S., Ji H., Liu L., 2013, Simulation of multiphase flow of the oil-water separation in a rotating packed bed for oil purification, Hindawi Publishing Corporation Mathematical Problems in Engineering, 1-9. 